\title{
Educational Aspirations of High School Graduates in British Columbia
}

\author{
JOHN D. DENNISON*
}

\section{Introduction}

No phenomenon in post secondary education has attracted more attention in the last three years than the erratic patterns of enrolment in the various institutions of higher learning. The relatively consistent, and largely predictable, yearly increases in student numbers observed during the sixties has taken a new direction which appears to be duplicated across the nation. University enrolments, particularly in the humanities, have leveled and, in some cases, declined, during the last two years. Enrolments in alternative institutions, colleges and technical schools, seem to be stabilizing at a much faster rate than had been anticipated. Recent publications of the Economic Council of Canada(1), in making reference to this new phenomenon, have indicated a degree of perplexity and warned that the traditional indicators of enrolment are of little value in making accurate predictions.

Faced with the development of a similar situation in British Columbia, it was decided that some structured attempt should be made to examine this pattern and perhaps shed some much needed light on the behaviour of the college-age population. Essentially, it was decided to explore the goals, aspirations, and intentions of graduating high school students to determine if these data would provide an explanation for the present situation and some prediction for the future.

\section{Design of the Study}

As part of a three year study of the Impact of Community Colleges in British Columbia (2), the relative status of the colleges in the broad spectrum of higher education became an important area for research.

Originally, the objective was to determine how the college was regarded by high school graduates and what effect the presence of a college in their immediate district would have upon their intentions in post-secondary education. In actual fact, the study assumed much greater scope when the data were examined and broader insights than had been generally anticipated came to realization.

A questionnaire was designed for completion by all graduating students from the 142

* John D. Dennison is Associate Professor, Department of Higher Education, University of British Columbia. 
high schools in the province of British Columbia. In May 1973, when the data were gathered, there were 26,613 students enrolled in Grade 12 in the province. Responses were obtained from 19,553 students in 138 schools, a response rate of $73.5 \%$. The questionnaire included a variety of items, ranging from "basic data," birth-date, sex, high school programme, anticipated academic average, etc., to specific questions regarding the students' intentions in post-secondary education: if they intended to continue, when, and in which institution. In addition, several items centered around socio-economic data, parents' education and occupations and general income levels. These data followed the format previously used for college and university students and was essentially comparable with the data gathered in the 1971 Canadian Census.

The vast amount of information collected in the study was summarized within a particular format and results were produced by individual school, by school district, by college district and for the province as a whole.

The timing of the study was given lengthy consideration. It was important to gather the data at a time when students were in a position to consider seriously their future plans and while they were still attending high school. It was apparent that the month of May seemed the best time to initiate the study and the results suggested that this was so.

\section{Results of the Study}

The province wide results of the study are best summarized as follows:

1 Approximately $90 \%$ of the students were in the $17-18$ age group while the female/male breakdown was $51.4 \%$ to $48.6 \%$ respectively.

2 Seventy per cent of the students were enrolled in the Academic Technical program which leads to university entrance.

3 In terms of approximate grade average, the students were clustered around the C+ category. However, while $26 \%$ indicated that they would rank in the top third of their grade, $68 \%$ chose the middle third and only $6 \%$ the lower third.

4 One quarter of the students had "no idea" as to the highest level of education they expected to attain. Another $15 \%$ expected to graduate from high school while $28 \%$ expected to graduate from university.

5 With regard to the most important influence upon their educational plans, by far the greatest single percentage, $35 \%$, checked their parents.

6 In response to a question concerning the area from which they expected their greatest satisfaction in life, the order reported was marriage and family, leisure time activities, and careers or occupations.

7 Socio-economic data, particularly with regard to parents occupation, suggested that high school graduates represented a lower socio-economic group than those students, which previous studies had indicated, attended college or university. However, it was apparent from data presently available that high school graduates represented a higher socioeconomic group than the population at large.

8 With regard to their immediate choice of post-secondary institution, approximately $30 \%$ selected a community college, $26 \%$ a university and $11 \%$ a technical institute. Another $13 \%$ stated that they were undecided. 
9 Only $9 \%$ stated that they had no plans for any kind of post-secondary education. However, of the remainder, only $41 \%$ stated that they would continue in the coming fall and the rest stated that their intention was to travel or work for one or two years.

10 The most important factor in the choice of institution was the particular program offered followed by "close to home" and "low cost." The reputation of the institution, in terms of teaching and research, was rated much lower on the scale.

11 More than one third of the students expressed their intention of taking a part-time job as their main source of funds. Only $4 \%$ stated that they would take a loan while another $7 \%$ anticipated earning a scholarship or bursary.

\section{Implications arising from the Study}

A number of implications were evident as a result of an analysis of the data from the study. Some of these were not anticipated at the time at which the project was being designed.

It was clear that recent enrolment patterns in post-secondary education in part, reflected the intentions expressed by the high school graduates in the study. Although over $90 \%$ of the students indicated their intention to take some form of tertiary education, less than $50 \%$ reported that this step was imminent. Apparently, many students will pursue other interests for one or two years before enrolling in a post-secondary institution. The long term effects of this phenomenon are questionable. Indeed, it is possible that enrolments will begin to climb again after a period of apparent "no growth."

Without exception, the greatest single percentage of students from areas which contained a community college designated the particular college as their first choice of institution. This was true, not only in rural areas, but in cities which claimed universities within easy commuting distance. There are, doubtlessly, many reasons for this preference, including the comprehensive type curriculum, low cost, open-door admission policy or the growing appeal of the college concept. In any event, the need for colleges in reasonably large population centres of the province was apparent. Furthermore, the current college financing policy, which by its nature, creates an in-district and out-of-district fee structure, seems in serious need of reappraisal.

With respect to the question of socio-economic factors and their effects on post-secondary education patterns, the study indicated that the "selection process" begins long before high school graduation. The question of the "elitist" nature of the post-secondary education remains an important one but there seems to be a greater need to direct research into the school system to determine how and when the self-selection process begins.

There emerged a remarkable variation in response to some questions when the analysis on a school-by-school and district-by-district basis was carried out. On the other hand, the responses to other questions were noteworthy in their consistency. Certainly, geographic and economic factors seemed to play an important role in some differences but others are largely unexplained. It seems that study of the data by those with more intimate knowledge of the district involved is necessary to adequately explain some anomalies.

In general, the study introduced as many questions as it answered. It did throw substantial light on enrollment patterns, the status and appeal of the various alternatives in post-secondary education, and gave direction to certain needed changes in the system. To these ends, the process was a success. 


\section{Concluding Statement}

A certain amount of "follow up" is necessary before the full impact of the study can be assessed. Much of this "follow up" is currently being carried out. As part of the three year study, the characteristics of entering students in the various institutions of post-secondary education in the fall of 1973 are being analysed. The initial task is to determine how many of the high school graduates actually followed their "first choice" of institution. To this end, every college, university and vocational school in the province is being involved in the collection of data on their entering first year level students.

Eventually, it will be possible to profile two populations of high school graduates; those who are enrolled in post-secondary institutions and those who are not. The variables which discriminate between the two populations will be determined and it should be possible to state which factors, be they socio-economic, geographic or academic, predict post-secondary enrollment. The products of this kind of analysis are generally lacking in previous studies of this problem.

In the final analysis it is believed that the research will provide significant background data for those who are concerned with a vital reorganization of tertiary education in the province of British Columbia. This reorganization, already initiated by the new government of the province, will blueprint the structure of post-secondary education in the future.

Copies of the report are available on application to the author.

\section{Notes}

1 Economic Council of Canada, Canadian Higher Education in the Seventies, Information Canada, 1972.

2 "The Impact of Community Colleges in British Columbia"-a three year study conducted jointly by B.C. Research and the University of British Columbia and financed by a grant from the Donner Canadian Canadian Foundation. Principal researchers are: Alex Tunner (B.C. Research) and John D. Dennison (UBC). 